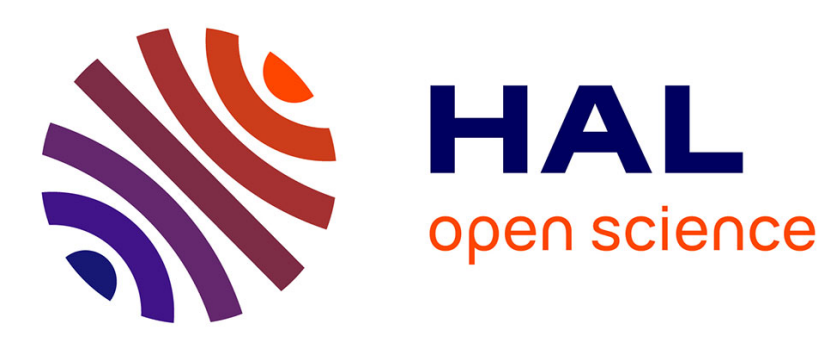

\title{
ADVANTAGES OF ac-EBIC IN DETERMINING THE SEMICONDUCTOR PARAMETERS
}

\author{
A. Romanowski
}

\section{To cite this version:}

A. Romanowski. ADVANTAGES OF ac-EBIC IN DETERMINING THE SEMICONDUCTOR PARAMETERS. Journal de Physique IV Proceedings, 1991, 01 (C6), pp.C6-83-C6-88. 10.1051/jp4:1991615 . jpa-00250700

\section{HAL Id: jpa-00250700 https://hal.science/jpa-00250700}

Submitted on 1 Jan 1991

HAL is a multi-disciplinary open access archive for the deposit and dissemination of scientific research documents, whether they are published or not. The documents may come from teaching and research institutions in France or abroad, or from public or private research centers.
L'archive ouverte pluridisciplinaire HAL, est destinée au dépôt et à la diffusion de documents scientifiques de niveau recherche, publiés ou non, émanant des établissements d'enseignement et de recherche français ou étrangers, des laboratoires publics ou privés. 


\section{ADVANTAGES OF AC-EBIC IN DETERMINING THE SEMICONDUCTOR PARAMETERS}

\section{A. ROMANOWSKI}

Institute of Electron Technology, Janiszewsiego 11/17, PL-50-372 Wroclaw, Poland

Abstract - The influence of trapping centres on the phase shift of the short circuit current generated by point source is analyzed. It is shown that maximum value of the phase corresponds to emission coefficient. Minority trapping centres of the $c u$ implanted $n^{+} p$ shallow junction are measured by ac-LBIC and ac-EBIC.

\section{1. - Introduction.}

Electron beam induced current (EBIC) technique was first used thirty years ago but it is still very attractive because it allows to determine some of the semiconductor parameters such as: diffusion length, lifetime, recombination at the defects, dislocations, grain boundaries. The recent work on EBIC has been concerned with the scanning analysis of the deep levels (SDLTS) $/ 1,2,3 /$. Among the others ac-EBIC technique seems to be promising in the SDLTS. Therefore we look briefly on influence of the deep levels on the short circuit current generated by electron or light beam. In theoretical analysis we take pattern upon von Roos works /4,5/. Next we describe the method of determining the capture cross section and activation energy. The verification of the method we carry on with $p-s i$ semiconductor implanted by cu.

\section{2.- Deep levels. Theory.}

The rate equation for a single trap is given by $16 /:$ 


$$
\frac{\partial \delta p_{T}}{\partial t}=c_{p} p n_{T}-e_{p} p_{T}-c_{n} n p_{T}+E_{n} n_{T}
$$

where $n_{T}+p_{T}=N_{T}$ and $N_{T}$ is the concentration of the trapping centres and from the neutrality condition $\delta n=\delta P_{T}+\delta p$. Thus in the linear approximation (low injection) the rate equation has a form:

$$
\frac{\partial \delta_{p_{T}}}{\partial t}={ }_{\tau_{t}}^{\delta p}-e_{p}^{*} \delta p_{T}
$$

$\tau_{t}$ is a lifetime of free cariers captured by traps and $e_{p}^{*}$ total emission of the trapped carriers :

$$
e_{p}^{*}=e_{p}(1+K), \quad k=\frac{p_{Q}}{p_{1}}+k_{p}
$$

where $e_{p}\left(=\tau_{T}{ }^{-1}\right)$ is emission of the trapped carriers while $k_{p}=\frac{c_{n} n_{0}}{c_{p} p_{1}}$ and $i f k_{p} \ll 1$ then the centre behaviours $1 i k e$ a trapping centre and for $k_{p} \gg 1$ the recombination process dominates $/ 6 /$, and $e_{p}=c_{p} p_{1}$.

\section{Neutral region:}

The transport diffusion equation for the first Fourier harmonic $\delta_{p}$ with uniform distribution of the traps has a form $/ 7 /$ :

$$
\Delta \delta p-\lambda^{* 2} \delta p=-G / D
$$

where $\Omega_{T}=\omega \tau T, \Omega=\omega \tau, L^{2}=D \tau$. If $\Omega<\tau / \tau_{t}<<1$ then:

$$
\operatorname{Im} \lambda^{*} \simeq \frac{1}{2 L} \frac{\tau}{\tau} \frac{\Omega_{T}}{(1+k)^{2}+\Omega_{T}^{2}}
$$

For shallow junction $/ 8 / I_{s c} \propto \exp \left(-\lambda^{*} h\right)$ and short circuit current is equal to:

$$
I_{s c}=A e^{-i \phi}
$$

where $h$ is the distance between the point generation source and the edge of the depletion layer. From (4) the phase shift is given by:

$$
\phi=\frac{\tau}{2 \tau} t \frac{h}{L} \frac{\Omega_{T}}{(1+K)^{2}+\Omega_{T}^{2}}
$$

and the phase reaches maximum value for $\Omega_{T}=1+K$. Thus knowing chopping frequency $\omega_{0}$ when a phase takes the maximum value we can find the 
emission coefficient:

$$
e_{p}=\frac{\omega_{D}}{1+K}=\frac{\omega_{Q}}{f^{-1}\left(E_{T}\right)+k}
$$

where $f(E)$ is Fermi distribution function.

\section{Depletion layer:}

The continuity equation for excess carriers for the first fourier component is equal to $17 /$ :

$$
\frac{\partial \delta_{p}}{\partial x}+\gamma \delta p=G / v_{s}
$$

where $v_{s}$ is drift velacity and $\operatorname{Im} \gamma=\frac{1}{\tau_{t} v_{S}} \frac{\Omega_{T}}{1+\Omega_{T}^{2}}+\frac{\omega}{v_{s}}$.

Thus the short circuit current generated by the point source placed at the depleted region is equal to:

$$
I_{s c}=q G_{t} e^{-\gamma h}
$$

where $h$ is distance between the edge of the depleted region and the point source ( $h \leq w$, $w$ is depletion layer width). From (9) the short circuit current may be expressed by (5) with the phase shift:

$$
\phi=\frac{h}{\tau_{t^{2}}} \frac{\Omega_{T}}{1+\Omega_{T}^{2}}
$$

where $\tau / \tau_{t}>>\Omega$ was assumed. This time the phase reaches the maximum value for $\Omega_{\mathrm{T}}=1$ or $e_{\mathrm{p}}=\omega_{\mathrm{a}}$.

\section{3.- Measurement.}

The discussion above shows that we can determine the deep level parameters either by changing a frequency or a temperature. In our measurement we scanned temperature, however in SDLTS application the frequency variation is more valuable. The measurement set up is shown in $f i g .1$, the capacitor had a value $10 \mu \mathrm{F}$ and temperature ranged from $77 K$ to $310 K$. Selective input amplifier of the lock-in was tuned to the chopping frequency $f$.

The applied sample was $n+p$ junction diode with diameter $320 \mu m$ and $p-5 i$ substrate material ab. lo囚cm. Before junction formation the cu was implanted with dose of $10^{13} \mathrm{~cm}^{-2}$ at $175 \mathrm{kV}$, next the sample was annealed 


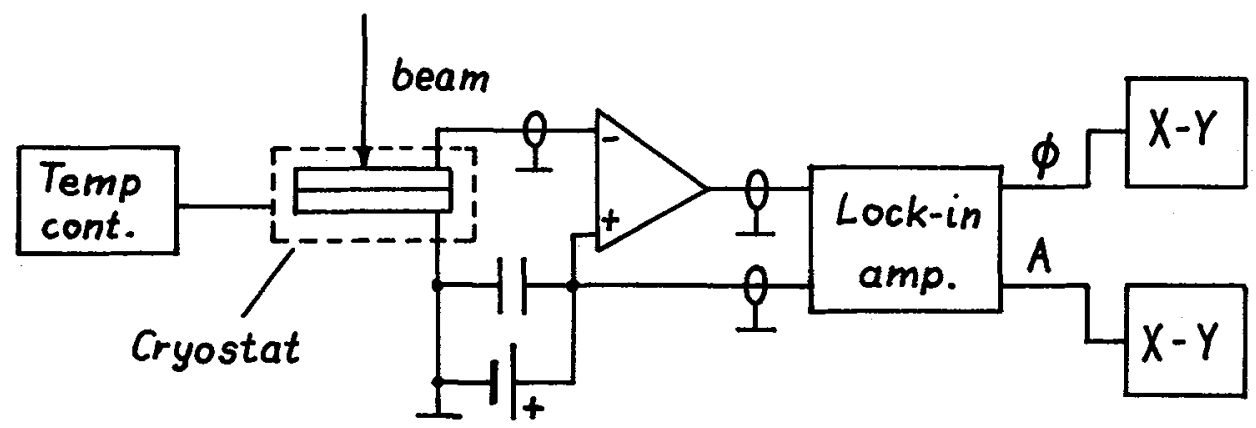

Fig. 1.- Apparatus for ac-LBIC and ac-EBIC

for somin at $620^{\circ} \mathrm{C}$ in dry nitrogen. The junction was formed by implantation $P$ on the face and $B$ on the back. The TiW-Au was used for the top contact $r i n g$ and $A l$ for back ohmic contact. Shallow doping concentration and deep levels were detected by DLTS type DLSBZE in C-DLTS mode as well as in photo C-DLTS mode. The DLTS characteristic showed two visible maxima well documented in literature /9/ with $\mathrm{E}_{v}$ + $0.266 e V$ and $E_{v}+0.430 e V$. Minority carrier trap was observed only for low temperature and signal had no extremum. However the photo C-DLTS with 890nm GaAlAs LED revealed another two traps: $E_{v}+0.1 e V$ (probably the hole trap in $n^{+}$layer formed by $V^{-}$vacancy) and $E_{c}-0.499 e V$ (Au level in p region).
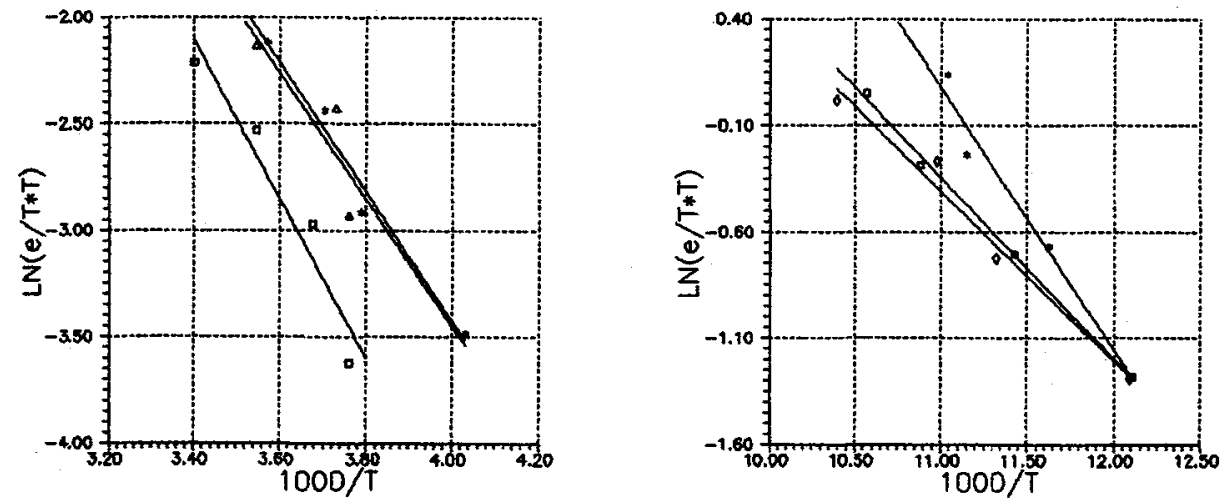

Fig.2. - LBIC Arhenius diagrams for $U_{R}=0-O V, \Delta-3 V$, $\diamond-4 V, *-5 V ;$ (a) first trap, (b) second trap 
Knowing the deep centres of the sample we measured the activation energy using the ac-LBIC with Bgonm LED and next we used ac-EBIC. In fig.2a the Arhenius plots for the first trap are shown $\omega_{k}=0,3$, and SV) while in fig.2b for the second $U_{k}=3,4$ and $5 V$. Calculated activation energy were equal : - first trap $E_{V}+0.075 e V\left(U_{R}=0,3 V\right)$ and $E_{V}+0.068 e V$ for $U_{R}=5 V ;-s e c o n d$ trap $E_{c}-0.323 e V\left(U_{k}=3 V s, E_{c}\right.$ - $0.261 e V\left(U_{F}=4\right.$, 5V). We hope that discrepancy between the data (LEIC and DLTS) is caused by recambination process. For the first trap $f(E) \simeq$ 1 and for the second one $f(E) \simeq 0$ therefore from (2):

$$
e_{p}^{*} / e_{p}=1+k_{p} \quad \text { and } \quad e_{n}^{*} / e_{n}=1+k_{n}
$$

thus comparing Arhenius plots for LBIC and DLTS we have $k_{p} \simeq 3, k_{n} \simeq$ 14.6. It means that in both cases the demarcation level lay between free carrier band and trapping level.
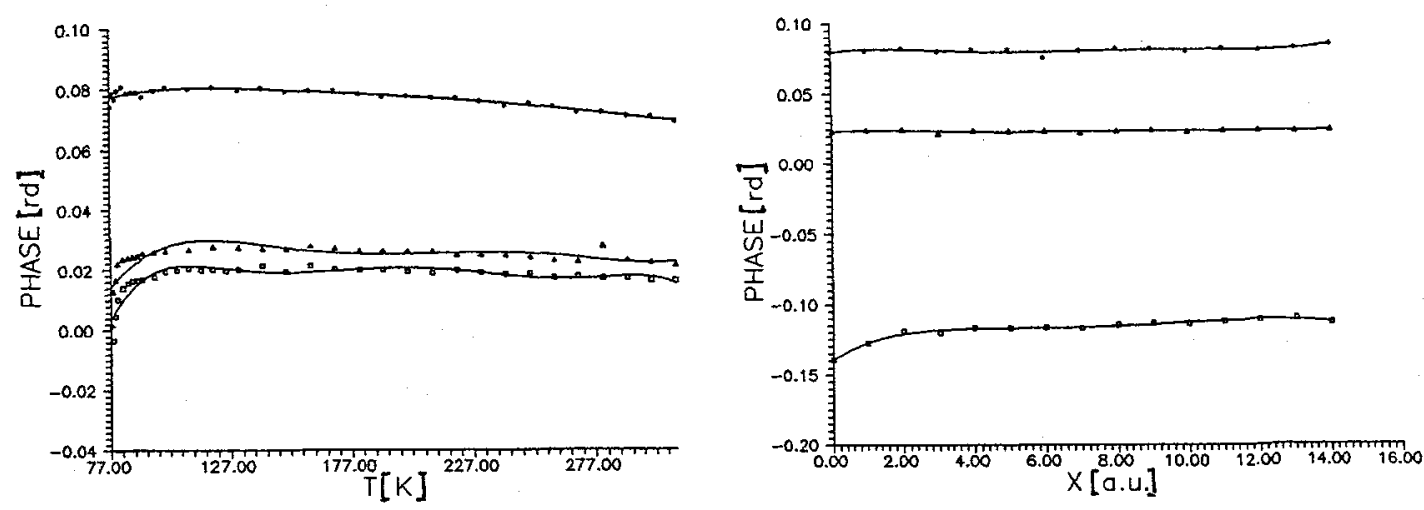

Fig.3.- EBIC-phase vs temperature, $U_{0}=10 \mathrm{kV}, U_{R}=7 \mathrm{~V}$ and frequencies: $\square-40 \mathrm{BHz}, \Delta-603 \mathrm{~Hz}, *-999 \mathrm{~Hz}$

Fig.4.- EBIC-phase vs position of scanning beam, $U_{a}=10 \mathrm{kV}$, $\mathrm{U}_{\mathrm{R}}=7 \mathrm{~V}, \mathrm{~T}=100 \mathrm{~K}, \square-401 \mathrm{~Hz}, \Delta-601 \mathrm{~Hz}, * 1008 \mathrm{~Hz}$

( 2 units on $x$ axis corresponds to $20 \mu \mathrm{m}$ )

The great adventage of EBIC over LEIC is the possibility of changing the penetration depth $h$. But because of small generation volume the phase shift in the EBIC is much smaller then in the LBIC. For instance in fig.3 the phase vs temperature is shown for accelerating voltage $U_{0}$ $=10 k V$. From the Arhenius plot the trapping level is equal to $E_{c}-$ $0.08 e V$ what agrees well with the LBIC measurement. We did not find the second trap. The same was with $U_{0}=20 k \mathrm{~V}$. Figure 4 shows the phase vs 
position of the scanning electron beam along sample diameter.

\section{4. - Conclusions.}

We described a simple method of determining of the minority carriers traps (activation energy and capture cross section) by ac-EBIC or ac-LEIC. The method was verified on implanted $n^{+} p$ junction with two minority carriers traps. The two traps were confirmed by ac-LBIc method and only one by ac-EBIC. We suspect that the second trap will also be found by EBIC but with high accelerating voltage and we think that discrepancy between DLTS and L/EBIC data are caused by recombination process.

\section{References}

1/ FETFOFF P,M, LANG D,V, Appl . Phys.Lett. 31 (1977).

/2/ BREITENSTEIN 0 , HEYDENREICH J, Scanning 7 (1985) 273.

/3/ BREITENSTEIN 0, EISENSCHMIDT CH, Microelec. Eng. 12 (1990) 171.

/4/ von RDOS 0, J.Appl. Phys.50 (1979) 3738.

/5/ von ROOS 0, J.Appl . Phys.51 (1980) 4523.

/6/ AUTH J, GENZOW D, HERMAN K, H, Photoelektrische Erscheinungen, Akademie-Verlag, Berlin 1977.

17/ ROMANOWSKI A, Investigation of Semiconductors by the Electronovoltaic Methods, Prace ITE Pol. Wrac. 39 (14), Wroctaw 1990 (in pol ish).

/8/ ROMANOWSKI A, KORDAS L; MULAK A, Scanning 11 (1989) 207.

/9/ BRDTHERTON $S, D$, AYRES $J, R$, GILL $A$, van KESTEREN $H, W$, GREIDANUS $F$, J.Appl.Phys.62 (1987) 1826. 